\title{
Assessing multiple sclerosis-related quality of life among Iranian patients using the MSQOL-54 tool: a cross-sectional study
}

Shadi Ziaie ${ }^{1}$, Niloofar Namazi ${ }^{1}$, Golnaz Afzal ${ }^{2}$, Saghar Barati ${ }^{1}$, Rezvaneh Mohebbi ${ }^{1}$, Mahshad Mir ${ }^{1}$, Hadi Esmaily ${ }^{1 *}$ and Gholamhossein Mehralian ${ }^{3^{*}}$

\begin{abstract}
Background: Multiple sclerosis (MS) is a chronic autoimmune disease and is one of the most costly medical conditions that imposed families with catastrophic health expenditures. There is an increasing trend in using alternative medicines including, dietary supplements, herbs, vitamins, and minerals. To date, the association between dietary as well as herbal supplements and QoL in MS patients is under researched; thus, this study aimed to assess the association between the self-reported supplement used and QoL between MS patients.

Methods: This cross-sectional study was conducted on patients with MS referring to Shahid Kazemi Pharmacy, based in the city of Tehran, Iran, as a national pharmacy providing specialized pharmaceutical products and pharmaceutical care to patients. The Multiple Sclerosis Quality of Life-54 (MSQoL-54) tools was performed to evaluate MS patients QoL.
\end{abstract}

Results: A total number of 382 patients with MS participated in this study. They include 89 (23.3\%) men and 293 (76.7\%) women, aged $40 \pm 10.9$ years old. The overall score of the MSQoL-54 questionnaire was 41.58 out of 100. Physical health composite (PHC) and mental health composite (MHC) were 69.60 and 62.99 from 100, respectively. This study revealed that $76.4 \%$ of patients used at least one vitamin daily; $92.4 \%$ of patients do not receive any herbal product. Vitamin D is the most widely used supplement, followed by calcium, while vitamin C is the least consumed. No correlation was observed regarding supplement use and overall QoL, PHC, or MHC. There were no significant differences between QoL's dimensions score in patients who used supplements. The results showed that increasing the number of supplements used did not relate to overall QoL, PHC, or MHC. In addition, there was not any correlation between the duration used of supplements and QoL's dimensions score in MS patients ( $p$-value> 0.05).

Conclusions: The dietary supplement appears to be popular among MS patients. The study results showed that the number of supplementations and their long-term use in patients with MS were not associated with higher QoL. Similarly, the herbal supplements have failed to improve QoL.

Keywords: Dietary supplement, Sclerosis, multiple, Health-related quality of life, Multiple sclerosis quality of Life-54, Iran

\footnotetext{
*Correspondence: esmaily_hadi@yahoo.com; Gmehralian@gmail.com

'Department of Clinical Pharmacy, School of Pharmacy, Shahid Beheshti University of Medical Sciences, Tehran, Iran

${ }^{3}$ Department of Pharmaco-economics and Pharma Management, School of Pharmacy, Shahid Beheshti University of Medical sciences, Tehran, Iran

Full list of author information is available at the end of the article
} 


\section{Background}

Multiple Sclerosis (MS) is known as the major autoimmune demyelinating disease of the central nervous system (CNS) and even one of the main causes of disabilities, high healthcare costs, and mortality in young adults [1-3]. The reported cases of MS in 2016 have shown 2,221,188 patients living with MS across the world [4]. Iran is also a country with a high prevalence rate of MS in the Middle East. In 2019, the incidence of MS among Iranians had been similarly reported to range from 7 to 148.1/100,000 [5]. Patients with MS often reported the role limitations due to a wide variety of MS symptoms such as spasms, ataxia, vertigo, fatigue, sexual dysfunction, pain, vision loss, paresis, urinary or fecal sphincter dysfunction, and tremor [6, 7]. Besides, MS negatively impacts cognitive and psychological functions, impacting their health-related quality of life (QoL) [810].

Research has shown that patients with MS have lower QoL than the general population and suffer from other chronic neurological disorders like Parkinson's disease and epilepsy [11].

Knowledge of which factors could influence QoL in patients with MS is critical, enhancing health authorities and policymakers in clinical decision-making and assisting them in choosing the most appropriate interventions [12-14]. It has largely focused on the dietary supplement as one of the possible environmental factors with QoL's physical and mental dimensions such as MS symptomatology and psychological status [15]. Some studies showed that the pattern of dietary supplements used among MS patients is increasing [16, 17]; up to $70 \%$ of patients with MS have tried one or more complementary and alternative medicine treatments for their disease [18]. Therefore, MS patients are frequently interested in using supplements to improve their QoL $[16,19]$. The evidence clearly shows that supplying accessories would increasingly cost patients [20]. while it is found, there is no always a significant positive relationship between costs of MS and patient's QoL [21-23].

The finding of several clinical studies in MS patients has demonstrated that some dietary supplements could decrease the severity of MS symptoms and thus improve QoL [15, 24-28]. At the same time, there are few studies examining associations between self-reported supplement use and MS patient's QoL [29]. On the other hand, there is no effective clinical indication authorized by food and drug agencies for applying dietary supplementation against MS symptomatology and enhancement of QoL $[15,30]$. Furthermore, there is very limited research evaluating the relationship between the real-world supplement used and dimensions of QoL such as physical and MHC in MS patients. In the other word, the role of minerals, trace elements, antioxidants, and vitamins, which has received increased attention in the past decade among MS patients on QoL, is unclear. However, it is essential to evaluate the QoL as a significant clinical outcome in patients with MS and assess the role of the dietary supplement used in the real world on QoL among patients with MS [15, 31, 32].

Several measurement tools of QoL have been identified [13]. However, MS patients' QoL is often measured by the Multiple Sclerosis Quality of Life-54 (MSQoL-54) questionnaire, which has been typically practiced in clinical studies in recent years [12, 33]. In this sense, we used the MSQoL-54 as the most common and standardized disease-specific questionnaire to assess QoL in patients with MS [34] based on the generic SF-36 QoL instrument [35]. Therefore, the objectives of the present study were to assess QoL, pattern dietary supplement usage among patients living with MS, and identify if the type of supplements used could be related to improve QoL.

\section{Methods \\ Study design}

This cross-sectional study was conducted from February 2019 to March 2020 at Shahid Kazemi Pharmacy in Tehran, Iran, as a national pharmacy providing specialized pharmaceutical care to patients with MS. The Ethics Committee also approved this study of Shahid Beheshti University of Medical Sciences, Tehran, Iran, with the registry code of IR.SBMU.PHARMACY.REC.1398.240.

\section{Study population and data collection}

The patients affected with MS referring to the pharmacy concerned were invited to participate in this study. After scrutinizing their prescriptions, additional questions were further raised to ensure that the patients had been diagnosed with MS. To be included in the study, the cases needed to be older than 18 years and at least 6 months of MS diagnosis. Written informed consent was also given to the patients before their inclusion, and they were allowed to withdraw from the study whenever they desired. The sample size was calculated using Cochran's formula. According to the statistics released by the Iranian MS Society, the number of patients with MS in Iran was 68,192 cases. In this formula, the confidence interval (CI) of $1.96 \mathrm{Z}$-score was $95 \%$, and the $p$ value, as the ratio of the attribute in the society, was equal to 0.5. Besides, the margin of error (D) in this study was 0.05 . The sample size was further estimated to be 382 individuals.

\section{Questionnaire development}

The validated Persian version of the MSQoL-54 questionnaire was applied to collect the required data, whose 
Table 1 Demographic and clinical characteristics of patients $(n=382)$

\begin{tabular}{ll}
\hline Variable & N (\%) or Mean \pm SD \\
\hline Age, years (mean \pm SD) & $40 \pm 10.9$ \\
Gender (male) & $89(23.3 \%)$
\end{tabular}

Marital status

Single

$154(40.3 \%)$

Married

$228(59.7 \%)$

level of education

Undergraduate

$27(7.1 \%)$

Diploma

102(26.7\%)

Associate degree

$15(3.9 \%)$

Bachelor

152(39.8\%)

Master

$64(16.8 \%)$

Professional doctoral degree

$22(5.8 \%)$

Job

Unemployed

$28(7.3 \%)$

Freelance

$134(35.1 \%)$

Government

Housewife

Student

$16(4.2 \%)$

$168(44 \%)$

$13(3.4 \%)$

Retired

$23(6 \%)$

Income

No income

1-5 million toman/month

5-10 million toman/month

$>10$ million toman/month

Physical activity

Low

Moderate

High

\section{Comorbidity}

Heart disease

$6(1.6 \%)$

Diabetes

Hypertension

Hypothyroid

$214(56 \%)$

$81(21.2 \%)$

$62(16.2 \%)$

$25(6.5 \%)$

$246(64.4 \%)$

$88(23 \%)$

$48(12.6 \%)$

$7(1.8 \%)$

15 (3.9\%)

$20(5.2 \%)$

$2(0.5 \%)$

$6(1.6 \%)$

$1(0.3 \%)$

$19(5 \%)$

$111 \pm 78$

Duration of $\mathbf{M S}^{*}$ disease, months

\section{MS subtype}

RRMS*

PMS*

$354(92.7 \%)$

$28(7.3 \%)$

Mode of MS medication administration

Oral

$254(66.5 \%)$
Table 1 Demographic and clinical characteristics of patients $(n=382)$ (Continued)

\begin{tabular}{ll}
\hline Variable & N (\%) or Mean \pm SD \\
\hline Injection & $128(33.5 \%)$ \\
Anti-depressant drugs & $1 \%$ \\
Tricyclic antidepressants & $1.7 \%$ \\
Selective serotonin reuptake inhibitors & $1.5 \%$ \\
Serotonin-norepinephrine reuptake inhibitor & $0.5 \%$ \\
Atypical & \\
Antianxiety drugs & $2.4 \%$ \\
anticonvulsant & $1.3 \%$ \\
benzodiazepines & $0.5 \%$ \\
Nonbenzodiazepines & \\
Supplements & $305(79.8 \%)$ \\
Yes & $77(20.2 \%)$ \\
No & $1 \pm 1.3$ \\
Number of daily supplements used & $79.2 \pm 105$ \\
Supplement used duration, months
\end{tabular}

MS Multiple sclerosis, RRMS relapsing-remitting Multiple sclerosis, PMS Progressive multiple sclerosis

acceptable reliability and construct validity had been already confirmed [36]. Notably, the MSQoL-54 is known as a health-related self-report questionnaire containing 54 items, categorized into 12 sub-scales: physical health (10 items), role limitations-physical (4 items), emotional well-being ( 8 items), pain (3 items), energy (5 items), health perceptions (5 items), social function (3 items), cognitive function ( 4 items), health distress (4 items), sexual function (5 items), change in health (1 item), and overall QoL (2 items). There was also one item under the theme of overall QoL, related to patients' views about overall assessment of their own QoL, labeled as "self-score" in this study.

Additionally, two composite scores, namely, physical health composite (PHC) and mental health composite (MHC), were measured by adding some sub-scales accordingly. The PHC includes eight sub-scales of physical function, health perceptions, energy/fatigue, role limitations-physical, pain, sexual function, social function, and health distress and the MHC is made up of five sub-scales: health distress, overall QoL, emotional wellbeing, role limitations-emotional, and cognitive function. The composite scores can be calculated by transforming the item scores to zero to 100 scales, with zero representing the worst health status and 100 indicating the best health status.

With respect to demographic data, characteristics such as age, gender, marital status, levels of education, job, income, physical activity, comorbidity (heart disease, diabetes, hypertension, hypothyroid, hyperthyroid, cancer, stroke, and depression), MS subtype, MS medication, 


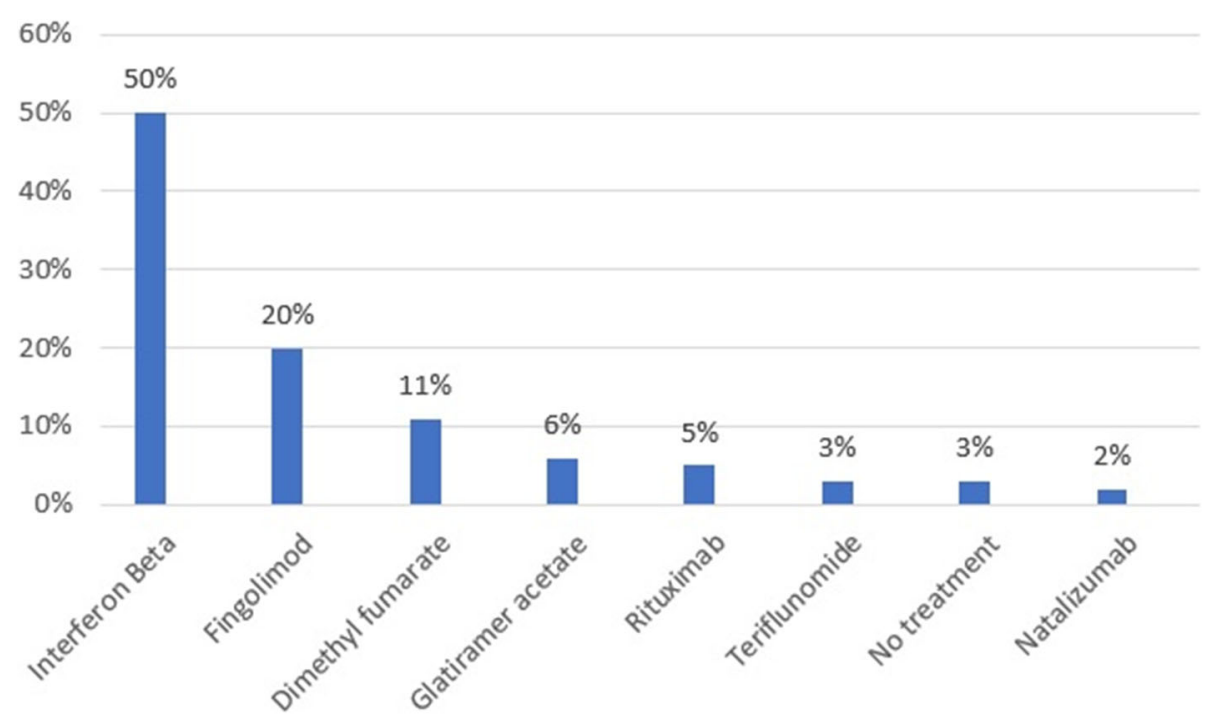

Fig. 1 Frequency distribution of medication among patients with multiple sclerosis ( $N$ : 382)

mode of administration, duration of MS disease, and the concomitant use of an anxiolytic agent or an antidepressant were asked (Table 1). The authors developed a structured self-administered questionnaire to measure the usage patterns of vitamins, minerals, herbals, and another dietary supplements with detailed information about the type, the number of supplements taken, and the continuity of taking supplements. Physical activity was measured using the SQUASH, a valid and reliable questionnaire to determine daily physical activity based on an average week in the past month in MS patients $[37,38]$. The SQUASH was also comprised of items on commuting activities, leisure-time and sports activities, household activities, and activities at work and school. Based on the reported efforts in the SQUASH questionnaire, the patients were divided into three classes according to their physical activity level as follows: low, moderate, and high [39].

\section{Statistical analyses}

Descriptive statistics were used for assessing all demographic data and the parameters related to patients' profiles. The Kolmogorov-Smirnov test was used to evaluate the distribution of the data. For comparisons, an independent sample t-test was used. Correlations

Table 2 The mean and standard deviation of MSQoL-54 dimensions among patients with multiple sclerosis

\begin{tabular}{lll}
\hline Variable & Mean score & SD \\
\hline Physical Health Composite & 69.60 & 18.38 \\
Mental Health Composite & 62.99 & 22.74 \\
Overall QoL score & 41.58 & 12.69 \\
\hline
\end{tabular}

QoL quality of life, $S D$ standard deviation between the physical, mental health composite and overall QoL scores with the other parameters such as; the number of supplement usage daily and supplement duration were evaluated using Pearson's correlation test. The level of significance was set at 0.05 . Statistical analyses were done using SPSS 23.0 software (SPSS Inc., Chicago, IL, USA).

\section{Results}

Over 15 months, a total number of 382 MS patients agreed to participate in the study, including 89 (23.3\%) men and 293 (76.7\%) women with the mean age of $40 \pm$ 10.9 years. The mean disease duration was also $111 \pm 78$ months ranged from 6 to 480 months. Based on the clinical subtype of MS, 354 (92.7\%) of patients were identified as RRMS, and 254 (66.5\%) received oral diseasemodifying therapies. Of the $382 \mathrm{MS}$ patients enrolled, $305(79.8 \%)$ used dietary supplements regularly daily. The mean duration of supplement usage was $79.2 \pm 105$. In this study, the concomitant use of antidepressant and anxiolytic drugs was just 4.7 and $4.2 \%$, respectively.

All other demographic characteristics of the participants are depicted in Table 1.

The frequency of MS medications taken by the patients indicates in (Fig. 1). Interferon beta was the most commonly prescribed medication to treat MS.

In addition, Table 2 presents that the overall score of the MSQoL-54 questionnaire among the patients with MS was $41.58 \pm 12.69$, and that was $69.60 \pm 18.38$ and $62.99 \pm 22.74$ respectively for the PHC and MHC.

The results of this study reveal that $76.4 \%$ of patients used at least one vitamin daily (Table 3 ). Figure 2 shows that only $7.6 \%$ of the patients received the herbal supplements. Vitamin D is the most widely used supplement, 
Table $\mathbf{3}$ Number of vitamins usage daily by patients with multiple sclerosis (N:382)

\begin{tabular}{ll}
\hline Number of vitamins usage daily & $\mathbf{N}(\%)$ \\
\hline None & $90(23.6)$ \\
One & $203(53.1)$ \\
Two & $60(15.7)$ \\
Three & $23(6)$ \\
Four & $6(1.6)$ \\
\hline
\end{tabular}

followed by calcium, while vitamin $\mathrm{C}$ is the least consumed.

Moreover, given the normality of data, parametric analysis was applied for all studies. Table 4 shows the comparison of QoL dimensions between 382 MS patients who received dietary and herbal supplements or not. Patients who take calcium had less physical health status. Besides, there was a significant inverse relationship between the consumption of herbal and vitamin $C$ supplements and patients' overall QoL. In contrast, those receiving iron products were associated with more $\mathrm{PHC}$ sore.

Table 5 shows that an increase in the number of supplements used did not relate to overall QoL, PHC, or MHC. No correlation was further observed regarding the supplement use duration in terms of overall QoL, $\mathrm{PHC}$, or MHC ( $p$-value> 0.05).

\section{Discussion}

This study aimed to determine the self-reported prevalence and types of dietary and herbal supplement use in MS patients and assess the role of dietary supplementation on the QoL of MS patients. The results confirm that a large proportion $(79.8 \%)$ of MS patients in this study use supplements. The most common supplements reported were vitamin $\mathrm{D}$, followed by calcium and vitamin B groups. This study suggests that daily supplementation with herbal, vitamin $C$, iron products, and calcium can significantly associate with a different part of QoL dimensions. Consistent with prior research [40-42], our study showed an increasing trend in using supplementary and alternative medicines among MS patients. For example, O'Connor et al. found that the frequency of dietary supplement use was about $82.1 \%$ among MS patients [16]. Another study was conducted in the USA reported that $44.8 \%$ of patients with MS used vitamins [19]. We found that $76.4 \%$ of MS patients used at least one vitamin daily. Additionally, our results showed that just $7.6 \%$ of MS patients used herbal supplements, ranging from 26 to $80 \%$ in other studies [ 40 , 42, 43].

Differences among these studies may be due to different geographic areas, varied supplements studied, various categorizing patterns, and cultural differences [16, 19, 41]. The most commonly used dietary supplement by MS patients in our study was vitamin D. These results are similar to trends found in the published studies $[15,44]$. The clinical effect of vitamin D on MS patient's QoL is contradictory [45, 46]. Our findings favored those who did not confirm the significant impact of vitamin D on improved QoL.

It can be explained by decreased serological and metabolic responsiveness to vitamin $\mathrm{D}$ supplementation by patients with MS. To address this concern, higher doses

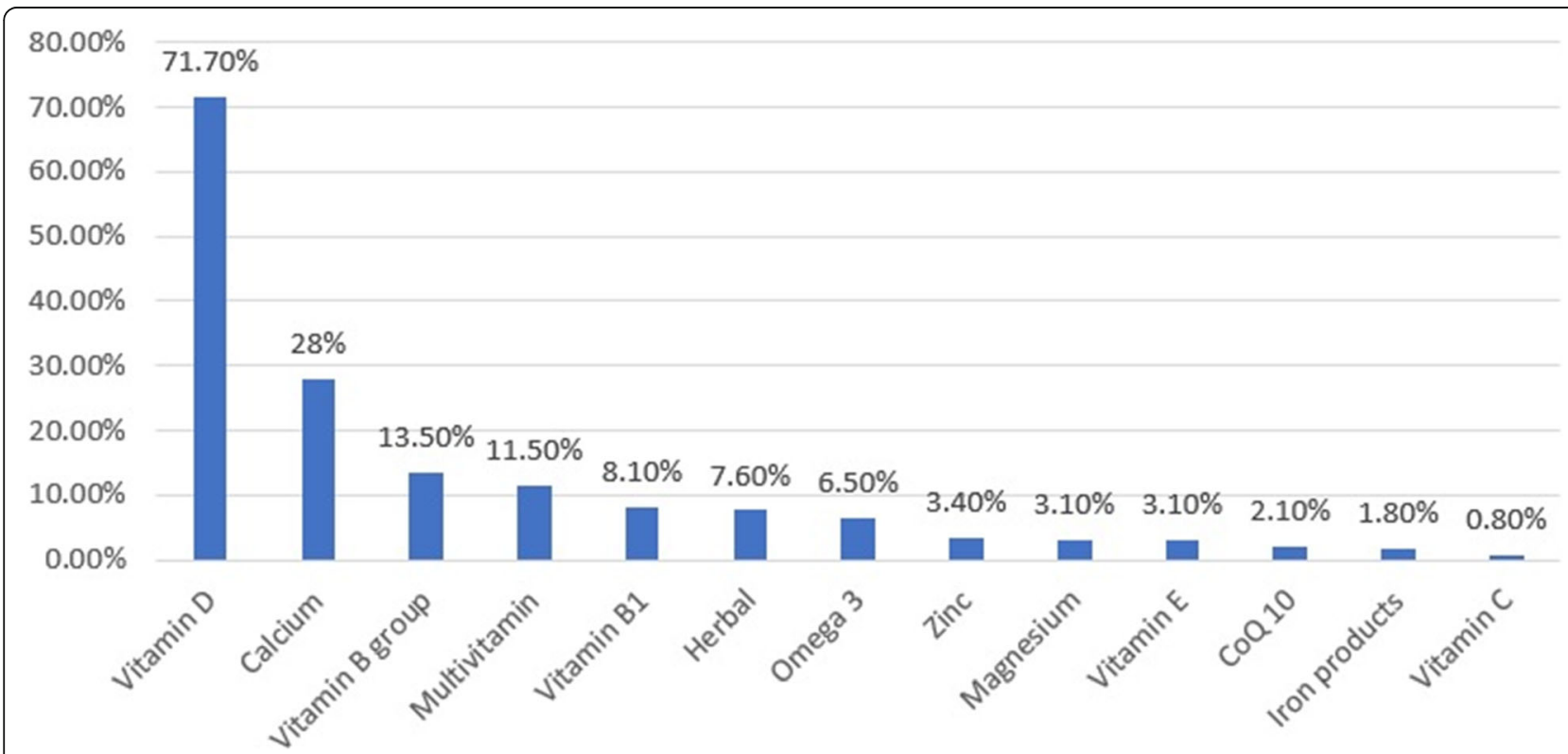

Fig. 2 Frequency distribution of the dietary and herbal supplements among patients with multiple sclerosis (N: 382) 
Table 4 Comparison of QoL dimensions between 382 patients with multiple sclerosis who received the dietary and herbal supplement

\begin{tabular}{|c|c|c|c|c|c|c|}
\hline Treatment & $\begin{array}{l}\text { Physical health } \\
\text { (Mean } \pm \text { SD) }\end{array}$ & $\mathrm{PV}^{*}$ & $\begin{array}{l}\text { Mental health } \\
(\text { Mean } \pm \text { SD) }\end{array}$ & $\mathrm{PV}^{*}$ & $\begin{array}{l}\text { Overall QoL } \\
\text { (Mean } \pm \text { SD) }\end{array}$ & $\mathrm{PV}^{*}$ \\
\hline \multirow[t]{2}{*}{ Vitamin D3 } & Yes: $114 \pm 8$ & 0.330 & Yes: $63 \pm 22$ & 0.271 & Yes: $41 \pm 12$ & 0.490 \\
\hline & No: $108 \pm 3$ & & No: $60 \pm 24$ & & No: $40 \pm 13$ & \\
\hline \multirow[t]{2}{*}{ Calcium } & Yes: $103 \pm 57$ & 0.038 & Yes: $59 \pm 22$ & 0.052 & Yes: $39 \pm 12$ & 0.076 \\
\hline & No: $116 \pm 58$ & & No: $64 \pm 22$ & & No: $42 \pm 12$ & \\
\hline \multirow[t]{2}{*}{ Vitamin B group } & Yes: $108 \pm 52$ & 0.557 & Yes: $62 \pm 19$ & 0.815 & Yes: $42 \pm 10$ & 0.317 \\
\hline & No: $113 \pm 59$ & & No: $63 \pm 23$ & & No: $41 \pm 13$ & \\
\hline \multirow[t]{2}{*}{ Multi vitamin } & Yes: $115 \pm 57$ & 0.746 & Yes: $64 \pm 21$ & 0.651 & Yes: $43 \pm 12$ & 0.343 \\
\hline & No: $112 \pm 58$ & & No: $62 \pm 22$ & & No: $41 \pm 12$ & \\
\hline \multirow[t]{2}{*}{ Vitamin B1 } & Yes: $109 \pm 51$ & 0.678 & Yes: $62 \pm 18$ & 0.826 & Yes: $43 \pm 9$ & 0.250 \\
\hline & No: $113 \pm 59$ & & No: $63 \pm 23$ & & No: $41 \pm 12$ & \\
\hline \multirow[t]{2}{*}{ Herbal } & Yes: $116 \pm 57$ & 0.852 & Yes: $61 \pm 20$ & 0.767 & Yes: $35 \pm 14$ & 0.040 \\
\hline & No: $113 \pm 59$ & & No: $63 \pm 23$ & & No: $42 \pm 12$ & \\
\hline \multirow[t]{2}{*}{ Omega-3 } & Yes: $92 \pm 55$ & 0.069 & Yes: $59 \pm 23$ & 0.394 & Yes: $40 \pm 11$ & 0.725 \\
\hline & No: $114 \pm 58$ & & No: $63 \pm 22$ & & No: $41 \pm 12$ & \\
\hline \multirow[t]{2}{*}{ Zinc } & Yes: $111 \pm 55$ & 0.932 & Yes: $62 \pm 19$ & 0.951 & Yes: $38 \pm 14$ & 0.404 \\
\hline & No: $113 \pm 58$ & & No: $63 \pm 22$ & & No: $41 \pm 12$ & \\
\hline \multirow[t]{2}{*}{ Magnesium } & Yes: $115 \pm 55$ & 0.871 & Yes: $62 \pm 19$ & 0.908 & Yes: $43 \pm 12$ & 0.519 \\
\hline & No: $112 \pm 58$ & & No: $63 \pm 22$ & & No: $41 \pm 12$ & \\
\hline \multirow[t]{2}{*}{ Vitamin E } & Yes: $129 \pm 54$ & 0.302 & Yes: $68 \pm 18$ & 0.374 & Yes: $37 \pm 15$ & 0.278 \\
\hline & No: $112 \pm 58$ & & No: $62 \pm 22$ & & No: $41 \pm 12$ & \\
\hline \multirow[t]{2}{*}{ Co Q10 } & Yes: $78 \pm 50$ & 0.091 & Yes: $54 \pm 25$ & 0.259 & Yes: $37 \pm 11$ & 0.302 \\
\hline & No: $113 \pm 58$ & & No: $63 \pm 22$ & & No: $41 \pm 12$ & \\
\hline \multirow[t]{2}{*}{ Iron product } & Yes: $168 \pm 13$ & $<0.01$ & Yes: $77 \pm 16$ & 0.097 & Yes: $41 \pm 15$ & 0.950 \\
\hline & No: $112 \pm 58$ & & No: $62 \pm 22$ & & No: $41 \pm 12$ & \\
\hline \multirow[t]{2}{*}{ Vitamin C } & Yes: $111 \pm 48$ & 0.948 & Yes: $55 \pm 10$ & 0.542 & Yes: $21 \pm 10$ & 0.006 \\
\hline & No: $113 \pm 58$ & & No: $63 \pm 22$ & & No: $41 \pm 12$ & \\
\hline
\end{tabular}

${ }^{*} P<0.05$ indicates significant difference

of vitamin $\mathrm{D}$ might be needed to have clinically relevant effects [47-49]. Similarly, such controversial results were found about herbal supplements [50, 51]. Our results showed that patients who received the herbal supplement had lower overall QoL. It could be argued that patients with lower QoL had felt disappointed with conventional therapies to control MS; they might show a higher willingness to use herbal supplements as complementary and alternative medicines.

Additionally, some herbal supplements may cause adverse reactions and interfere with MS conventional treatment; for example, herbal supplement containing echinacea may interfere with corticosteroids immunosuppressants [52-54]. Therefore, such an interaction

Table 5 Correlation of number and duration of supplements usage with QoL dimentions score

\begin{tabular}{|c|c|c|c|c|c|c|}
\hline \multirow[t]{2}{*}{ Variable } & \multicolumn{2}{|l|}{ PHC } & \multicolumn{2}{|l|}{ MHC } & \multicolumn{2}{|c|}{ Overall OoL } \\
\hline & Sig* & $r^{* *}$ & Sig* & $r^{* *}$ & Sig* & $r^{* *}$ \\
\hline Number of daily supplement & 0.309 & -0.052 & 0.512 & -0.034 & 0.376 & -0.045 \\
\hline Supplement used duration & 0.422 & 0.041 & 0.069 & 0.093 & 0.192 & 0.067 \\
\hline
\end{tabular}


may result from more demyelination and axonal loss, which leads to a vast number of troublesome MS symptoms and reduce QoL $[55,56]$.

The present study results showed that receiving more supplements could not increase overall QoL, PHC, and MHC. We also found no correlation between the duration of supplement use and QoL. In contrast, some clinical studies reported that the frequent use of nutritional supplements such as vitamin B12 and folic acid has a significant, positive effect on QoL of MS patients $[28,57]$. Therefore, more studies are needed to evaluate this effect using real-world studies.

On the other hand, Ernstsson $\mathrm{O}$ and et al. were also observed that medication and dietary supplements were the main cost drivers for MS patients [20]. Hence, given the increasing evidence for the significant reverse associations between costs related MS disease and patient's QoL [2123], no specific supplement was recommended to improve QoL in MS patients. With regard to the influence of calcium and iron on MS patient's QoL, our results showed that patients who received calcium had lower PHC, whereas who receive iron product had higher PHC. As it is well documented that certain micronutrient such as calcium and iron could control the progression of the MS disease, leading to improved QoL $[44,58]$, the reverse effect of calcium in this study might be related to this notion that the patients had already less physical activity status, it is consumed to postpone disease progression.

The findings were also consistent with earlier studies reporting that QoL was poor in patients living with MS $[59,60]$. As mentioned by Ruth Ann Marrie et al., underdiagnosed and undertreated depression had been one of the fundamental reasons for reduced QoL in MS [61]. This study also reported only a few patients using antidepressant or anxiolytic drugs to keep their QoL at higher levels. For this reason, it is recommended that due to the progressive and disabling nature of MS and the negative effects of depression on QoL, the patients should be continuously evaluated and appropriate pharmacotherapy is given if needed.

This study had some limitations that should be taken into account. First, MSQOL-54 has not been specifically validated for evaluating correlation between MS QoL and supplement usag. Second, self-report bias would be potentially another limitation across all studies using such a method. Coming together these limitations, it is of grate practical to continue research aimed at the assessment of other aspects of using dietary and herbal supplement by MS patients in terms of the economic status, social support, or rehabilitation needs.

\section{Conclusions}

Given the findings of this study, the dietary supplements appear to be popular among MS patients. Taking more supplements and their long-term usage were not posivitely associated with higher QoL. Similarly, the use of herbal supplements has failed to improve QoL. It is recommended to perform further self-reporting studies to evaluate the effectiveness of dietary and herbal supplements in enhancing MS-related QoL.

\section{Abbreviations}

MS: Multiple sclerosis; MHC: Mental Health Composite; MSQOL-54: Multiple sclerosis quality of life-54 questionnaire; PHC: Physical Health Composite; QOL: Quality of life

\section{Acknowledgements}

Authors would like to acknowledge the colleagues working in Shahid Kazemi pharmacy for their support and help.

\section{Authors' contributions}

Z.SH: Designer of the study. N.N: collected the required data. A.G: has analyzed, drafted and revised the work. E. H and B. S participated in the design of the study and developed the research question. M. R and M. M analyzed the data using the SPSS software program.

M.GH: coordinated the study, participated in its conception and its design, and reviewed the manuscript. All authors contributed to and have approved the final manuscript.

\section{Funding}

The study was funded by the authors them self's.

\section{Availability of data and materials}

The datasets used and/or analyzed during the current study are available from the corresponding author on reasonable request.

\section{Declarations}

\section{Ethics approval and consent to participate}

This study was conducted in accordance with the Declaration of Helsinki: hence the process of the survey was explained to the patients and, written informed consent was provided prior to enrollment. The protocol of study was approved by the Ethics Committee of Shahid Beheshti University of Medical Sciences, Tehran, Iran with the registry code of IR.SBMU.PHARMACY.REC.1398.240.

Consent for publication

Not applicable.

\section{Competing interests}

The authors declare that they have no competing interests.

\section{Author details}

'Department of Clinical Pharmacy, School of Pharmacy, Shahid Beheshti University of Medical Sciences, Tehran, Iran. ${ }^{2}$ Department of Clinical Pharmacy, School of Pharmacy, Shahid Sadoughi University of Medical Sciences, Yazd, Iran. ${ }^{3}$ Department of Pharmaco-economics and Pharma Management, School of Pharmacy, Shahid Beheshti University of Medical sciences, Tehran, Iran.

Received: 17 November 2020 Accepted: 16 August 2021

Published online: 31 August 2021

\section{References}

1. Berer K, Krishnamoorthy G. Microbial view of central nervous system autoimmunity. FEBS Lett. 2014;588(22):4207-13. https://doi.org/10.1016/j. febslet.2014.04.007.

2. Sahraian MA, Sahebkar M, Dehghani R, Derakhshan-Jazari M, KazamiMoghaddam V, Kouchaki E. Multiple sclerosis-a disease on a dramatically rising trend in Iran: review of possible reasons. Iran J Neurol. 2017;16(1):3440.

3. Jones E, Pike J, Marshall T, Ye X. Quantifying the relationship between increased disability and health care resource utilization, quality of life, work productivity, health care costs in patients with multiple sclerosis in the US. 
BMC Health Serv Res. 2016;16(1):294. https://doi.org/10.1186/s12913-016-1 532-1.

4. Wallin MT, Culpepper WJ, Nichols E, Bhutta ZA, Gebrehiwot TT, Hay SI, et al. Global, regional, and national burden of multiple sclerosis 1990-2016: a systematic analysis for the global burden of disease study 2016. Lancet Neurol. 2019;18(3):269-85. https://doi.org/10.1016/S1474-4422(18)30443-5.

5. Azami M, YektaKooshali MH, Shohani M, Khorshidi A, Mahmudi L. Epidemiology of multiple sclerosis in Iran: A systematic review and metaanalysis. PLoS One. 2019;14(4):e0214738-e.

6. Oh J, Vidal-Jordana A, Montalban X. Multiple sclerosis: clinical aspects. Curr Opin Neurol. 2018;31(6):752-9. https://doi.org/10.1097/WCO. 0000000000000622.

7. Rae-Grant A, Day GS, Marrie RA, Rabinstein A, Cree BA, Gronseth GS, et al. Practice guideline recommendations summary: disease-modifying therapies for adults with multiple sclerosis: report of the guideline development, Dissemination, and Implementation Subcommittee of the American Academy of Neurology. 2018;90(17):777-88. https://doi.org/10.1212/WNL. 0000000000005347.

8. Macías Islas MÁ, Ciampi E. Assessment and impact of cognitive impairment in multiple sclerosis: an overview. Biomedicines. 2019;7(1):22. https://doi. org/10.3390/biomedicines7010022.

9. Jongen PJ, Heerings M, Ruimschotel R, Hussaarts A, Duyverman L, van der Zande A, et al. Intensive social cognitive treatment (can do treatment) with participation of support partners in persons with relapsing remitting multiple sclerosis: observation of improved self-efficacy, quality of life, anxiety and depression 1 year later. BMC Res Notes. 2016;9(1):375. https:// doi.org/10.1186/s13104-016-2173-5.

10. Sarısoy G, Terzi M, Gümüş K, Pazvantoğlu O. Psychiatric symptoms in patients with multiple sclerosis. Gen Hosp Psychiatry. 2013;35(2):134-40. https://doi.org/10.1016/j.genhosppsych.2012.10.011.

11. Jongen PJ. Health-related quality of life in patients with multiple sclerosis: impact of disease-modifying drugs. CNS Drugs. 2017;31 (7):585-602. https:// doi.org/10.1007/s40263-017-0444-X.

12. Bandari DS, Vollmer TL, Khatri BO, Tyry T. Assessing quality of life in patients with multiple sclerosis. Int J MS Care. 2010;12(1):34-41. https://doi.org/10. 7224/1537-2073-12.1.34.

13. Mitchell AJ, Benito-León J, González J-MM, Rivera-Navarro J. Quality of life and its assessment in multiple sclerosis: integrating physical and psychological components of wellbeing. Lancet Neurol. 2005;4(9):556-66. https://doi.org/10.1016/S1474-4422(05)70166-6.

14. Greenhalgh J, Long AF, Flynn R. The use of patient reported outcome measures in routine clinical practice: lack of impact or lack of theory? Soc Sci Med. 2005;60(4):833-43. https://doi.org/10.1016/j.socscimed.2004.06.022.

15. Tryfonos C, Mantzorou M, Fotiou D, Vrizas M, Vadikolias K, Pavlidou E, et al. Dietary supplements on controlling multiple sclerosis symptoms and relapses: current clinical evidence and future perspectives. Medicines (Basel). 2019;6(3):95. https://doi.org/10.3390/medicines6030095.

16. O'Connor K, Weinstock-Guttman B, Carl E, Kilanowski C, Zivadinov R, Ramanathan MJJon. Patterns of dietary and herbal supplement use by multiple sclerosis patients. J Neurol. 2012;259(4):637-44.

17. Alnahdi MA, Alsulayhim AK, Salem AHB, Masuadi E, Malik YA. Patterns and outcomes of complementary and alternative medicine use among adult patients with multiple sclerosis. Cureus. 2020;12(10):e10825. https://doi.org/1 0.7759/cureus. 10825

18. Yadav V, Shinto L, Bourdette D. Complementary and alternative medicine for the treatment of multiple sclerosis. Expert Rev Clin Immunol. 2010;6(3): 381-95.

19. Olsen S. A review of complementary and alternative medicine (CAM) by people with multiple sclerosis. Occup Ther Int. 2009;16(1):57-70.

20. Ernstsson O, Gyllensten H, Alexanderson K, Tinghög P, Friberg E, Norlund A. Cost of illness of multiple sclerosis - a systematic review. PLoS One. 2016; 11(7):e0159129. https://doi.org/10.1371/journal.pone.0159129.

21. McCrone $\mathrm{P}$, Heslin M, Knapp M, Bull P, Thompson A. Multiple sclerosis in the UK: service use, costs, quality of life and disability. PharmacoEconomics. 2008;26(10):847-60. https://doi.org/10.2165/0001 9053-200826100-00005.

22. Rotstein Z, Hazan R, Barak Y, Achiron A. Perspectives in multiple sclerosis health care: special focus on the costs of multiple sclerosis. Autoimmun Rev. 2006;5(8):511-6. https://doi.org/10.1016/j.autrev.2006.02.001.

23. Kobelt $\mathrm{G}$. Costs and quality of life of patients with multiple sclerosis in Europe. The Euro J Health Econ. 2006;7(Suppl 2):S24-33.
24. Sanoobar M, Dehghan P, Khalili M, Azimi A, Seifar F. Coenzyme Q10 as a treatment for fatigue and depression in multiple sclerosis patients: a double blind randomized clinical trial. Nutr Neurosci. 2016;19(3):138-43. https://doi. org/10.1179/1476830515Y.0000000002.

25. Tourbah A, Lebrun-Frenay C, Edan G, Clanet M, Papeix C, Vukusic S, et al. MD1003 (high-dose biotin) for the treatment of progressive multiple sclerosis: A randomised, double-blind, placebo-controlled study. Multiple sclerosis (Houndmills, Basingstoke, England). 2016;22(13):1719-31.

26. Bitarafan S, Saboor-Yaraghi A, Sahraian MA, Nafissi S, Togha M, Beladi Moghadam N, et al. Impact of vitamin a supplementation on disease progression in patients with multiple sclerosis. Arch Iranian Med. 2015;18(7): 435-40 DOI: 0151807/AIM.008.

27. Toghianifar N, Ashtari F, Zarkesh-Esfahani SH, Mansourian M. Effect of high dose vitamin D intake on interleukin-17 levels in multiple sclerosis: a randomized, double-blind, placebo-controlled clinical trial. J Neuroimmunol. 2015;285:125-8. https://doi.org/10.1016/j.jneuroim.2015.05.022.

28. Nozari E, Ghavamzadeh S, Razazian N. The effect of vitamin B12 and folic acid supplementation on serum homocysteine, Anemia status and quality of life of patients with multiple sclerosis. Clin Nutr Res. 2019:8(1):36-45. https://doi.org/10.7762/cnr.2019.8.1.36.

29. Simpson-Yap S, Jelinek P, Weiland T, Nag N, Neate S, Jelinek G. Self-reported use of vitamin $D$ supplements is associated with higher physical quality of life scores in multiple sclerosis. Mult Scler Relat Disord. 2021;49:102760. https://doi.org/10.1016/j.msard.2021.102760.

30. Goldberg P, Fleming M, Picard E. Multiple sclerosis: decreased relapse rate through dietary supplementation with calcium, magnesium and vitamin D. Med Hypotheses. 1986;21(2):193-200.

31. Rezapour A, Kia AA, Goodarzi S, Hasoumi M, Motlagh SN, Vahedi S. The impact of disease characteristics on multiple sclerosis patients' quality of life. Epidemiol Health. 2017;39. https://doi.org/10.4178/epih.e201700.

32. Nedjat S, Montazeri A, Mohammad K, Majdzadeh R, Nabavi N, Nedjat F, et al. Quality of life in multiple sclerosis compared to the healthy population in Tehran. Iran J Epidemiol. 2006;2(3):19-24.

33. Opara JA, Jaracz K, Brola W. Quality of life in multiple sclerosis. J Med Life. 2010;3(4):352-8.

34. Ibrahim EAAE, Gassoum A, IshagAgib IEl. Quality of life among Sudanese patients with multiple sclerosis in Khartoum state using (MSQoL-54) questionnaire. BMC Res Notes. 2019;12(1):1-4.

35. Vickrey BG, Hays RD, Harooni R, Myers LW, Ellison GW. A health-related quality of life measure for multiple sclerosis. Qual Life Res. 1995;4(3):187206. https://doi.org/10.1007/BF02260859.

36. Ghaem $H$, Haghighi AB, Jafari P, Nikseresht A. Validity and reliability of the Persian version of the multiple sclerosis quality of life questionnaire. Neurol India. 2007;55(4):369-75. https://doi.org/10.4103/0028-3886.33316.

37. Abonie US, Hoekstra F, Seves BL, Woude LH, Dekker R, Hettinga F. Associations between Activity Pacing, Fatigue, and Physical Activity in Adults with Multiple Sclerosis: A Cross Sectional Study. J Funct Morphol Kinesiol. 2020;5(2):43.

38. Beckerman H, de Groot V, Scholten MA, Kempen JCE, Lankhorst GJ. Physical activity behavior of people with multiple sclerosis: understanding how they can become more physically active. Phys Ther. 2010;90(7):1001-13. https:// doi.org/10.2522/ptj.20090345.

39. Wendel-Vos GCW, Schuit AJ, Saris WHM, Kromhout D. Reproducibility and relative validity of the short questionnaire to assess health-enhancing physical activity. J Clin Epidemiol. 2003;56(12):1163-9. https://doi.org/10.101 6/50895-4356(03)00220-8.

40. Mohammadi M, Rashidizad SA, Lashkari N, Ataei S, Haddadi R, Mahboobian MM. Supplement Therapy in Multiple Sclerosis: A Pharmacological View. Avicenna J Pharm Res. 2020;1 (1):37-45.

41. Leong E M, Semple S J, Angley M, Siebert W, Petkov J, McKinnon RA. Complementary and alternative medicines and dietary interventions in multiple sclerosis: what is being used in South Australia and why? Complement Ther Med. 2009;17(4):216-23.

42. Yadav V, Shinto L, Morris C, Senders A, Baldauf-Wagner S, Bourdette Dennis. Use and self-reported benefit of complementary and alternative medicine among multiple sclerosis patients. Int J MS Care. 2006;8(1):5-10.

43. Nayak S, Matheis RJ, Schoenberger NE, SCJCr S. Use of unconventional therapies by individuals with multiple sclerosis. 2003;17(2):181-91.

44. Bagur MJ, Murcia MA, Jiménez-Monreal AM, Tur JA, Bibiloni MM, Alonso GL, et al. Influence of diet in multiple sclerosis: a systematic review. Adv Nutr. 2017:8(3):463-72. https://doi.org/10.3945/an.116.014191. 
45. Achiron A, Givon U, Magalashvili D, Dolev M, Zaltzman S L, Kalron A, et al. Effect of Alfacalcidol on multiple sclerosisrelated fatigue: A randomized, double-blind placebo-controlled study. Mult Scler. 2015;21(6):767-75.

46. Ashtari F, Toghianifar N, Zarkesh-Esfahani SH, Mansourian M. Short-term effect of high-dose vitamin $D$ on the level of interleukin 10 in patients with multiple sclerosis: a randomized, double-blind, placebo-controlled clinical trial. Neuroimmunomodulation. 2015;22(6):400-4.

47. Miclea A, Bagnoud M, Chan A, Hoepner R. A Brief Review of the Effects of Vitamin D on Multiple Sclerosis. Front Immunol. 2020;11:781. https://doi. org/10.3389/fimmu.2020.00781.eCollection2020.

48. Bhargava P, Steele SU, Waubant E, Revirajan NR, Marcus J, Dembele M, et al. Multiple sclerosis patients have a diminished serologic response to vitamin D supplementation compared to healthy controls. Mult Scler J. 2016;22(6): 753-60. https://doi.org/10.1177/1352458515600248.

49. Bhargava P, Fitzgerald KC, Calabresi PA, Mowry EM. Metabolic alterations in multiple sclerosis and the impact of vitamin D supplementation. JCI Insight. 2017:2(19):e95302. 10.1172/jci.insight.95302.

50. Kim E, Cameron M, Lovera J, Schaben L, Bourdette D, RJMSJ W. American ginseng does not improve fatigue in multiple sclerosis: a single center randomized double-blind placebo-controlled crossover pilot study. 2011; 17(12):1523-6. https://doi.org/10.1177/1352458511412062.

51. Etemadifar M, Sayahi F, Abtahi S-H, Shemshaki H, Dorooshi G-A, Goodarzi M, et al. Ginseng in the treatment of fatigue in multiple sclerosis: a randomized, placebo-controlled, double-blind pilot study. 2013;123(7):480-6.

52. O'Connor K, Weinstock-Guttman B, Carl E, Kilanowski C, Zivadinov R, Ramanathan M. Patterns of dietary and herbal supplement use by multiple sclerosis patients. J Neurol. 2012;259(4):637-44. https://doi.org/10.1007/ s00415-011-6226-3.

53. Loraschi A, Bellantonio P, Bortolon F, Capra R, Cavalla P, Costantino G, et al. Use of herbal remedies by multiple sclerosis patients: a nation-wide survey in Italy. Neurol Sci. 2016;37(4):613-22. https://doi.org/10.1007/s10072-016-2 519-8.

54. Kennedy DA, Seely D. Clinically based evidence of drug-herb interactions: a systematic review. Expert Opin Drug Saf. 2010;9(1):79-124. https://doi.org/1 $0.1517 / 14740330903405593$.

55. Kes VB, Cengić L, Cesarik M, Tomas AJ, Zavoreo I, Matovina LZ, et al. Quality of life in patients with multiple sclerosis. Acta Clin Croat. 2013;52(1):107-11.

56. Motl RW, McAuley E, Snook EM, Gliottoni RC. Physical activity and quality of life in multiple sclerosis: intermediary roles of disability, fatigue, mood, pain, self-efficacy and social support. Psychol Health Med. 2009;14(1):111-24.

57. Weinstock-Guttman B, Baier M, Park Y, Feichter J, Lee-Kwen P, Gallagher E, et al. Low fat dietary intervention with $\omega-3$ fatty acid supplementation in multiple sclerosis patients. Prostaglandins Leukot Essent Fatty Acids. 2005; 73(5):397-404

58. Ramsaransing GS, Mellema SA, De Keyser J. Dietary patterns in clinical subtypes of multiple sclerosis: an exploratory study. Nutr J. 2009;8(1):36. https://doi.org/10.1186/1475-2891-8-36.

59. Zwibel HL, Smrtka J. Improving quality of life in multiple sclerosis: an unmet need. Am J Manag Care. 2011;17(5):S139.

60. Lysandropoulos A, Havrdova E. 'Hidden'factors influencing quality of life in patients with multiple sclerosis. Eur J Neurol. 2015;22:28-33. https://doi. org/10.1111/ene.12801.

61. Marrie RA, Patten SB, Berrigan LI, Tremlett H, Wolfson C, Warren S, et al. Diagnoses of depression and anxiety versus current symptoms and quality of life in multiple sclerosis. Int J MS Care. 2018;20(2):76-84.

\section{Publisher's Note}

Springer Nature remains neutral with regard to jurisdictional claims in published maps and institutional affiliations.

Ready to submit your research? Choose BMC and benefit from:

- fast, convenient online submission

- thorough peer review by experienced researchers in your field

- rapid publication on acceptance

- support for research data, including large and complex data types

- gold Open Access which fosters wider collaboration and increased citations

- maximum visibility for your research: over $100 \mathrm{M}$ website views per year

At BMC, research is always in progress.

Learn more biomedcentral.com/submissions 